\title{
Dominance of climate warming effects on recent drying trends over wet monsoon regions
}

\author{
Chang-Eui Park ${ }^{1}$, Su-Jong Jeong ${ }^{1}$, Chang-Hoi Ho ${ }^{2}$, Hoonyoung Park ${ }^{2}$, Shilong Piao ${ }^{3,4,5}$, Jinwon Kim ${ }^{6}$, and \\ Song Feng ${ }^{7}$ \\ ${ }^{1}$ School of Environmental Science and Engineering, South University of Science and Technology of China, \\ Shenzhen 518055, China \\ ${ }^{2}$ School of Earth and Environmental Sciences, Seoul National University, Seoul, 08826, South Korea \\ ${ }^{3}$ Key Laboratory of Alpine Ecology and Biodiversity, Institute of Tibetan Plateau Research, \\ Chinese Academy of Sciences, Beijing 100101, China \\ ${ }^{4}$ Sino-French Institute for Earth System Science, College of Urban and Environmental Sciences, \\ Peking University, Beijing 100871, China \\ ${ }^{5}$ Center for Excellence in Tibetan Earth Science, Chinese Academy of Sciences, Beijing 100085, China \\ ${ }^{6}$ Department of Atmospheric and Oceanic Sciences, University of California, Los Angeles, CA 90024, USA \\ ${ }^{7}$ Department of Geosciences, University of Arkansas, Fayetteville, AR 72701, USA
}

Correspondence to: Su-Jong Jeong (waterbell77@gmail.com)

Received: 15 January 2017 - Discussion started: 14 February 2017

Revised: 5 August 2017 - Accepted: 8 August 2017 - Published: 7 September 2017

\begin{abstract}
Understanding changes in background dryness over land is key information for adapting to climate change because of its critical socioeconomic consequences. However, causes of continental dryness changes remain uncertain because various climate parameters control dryness. Here, we verify dominant climate variables determining dryness trends over continental eastern Asia, which is characterized by diverse hydroclimate regimes ranging from arid to humid, by quantifying the relative effects of changes in precipitation, solar radiation, wind speed, surface air temperature, and relative humidity on trends in the aridity index based on observed data from 189 weather stations for the period of 19612010. Before the early 1980s (1961-1983), change in precipitation is a primary condition for determining aridity trends. In the later period (1984-2010), the dominant climate parameter for aridity trends varies according to the hydroclimate regime. Drying trends in arid regions are mostly explained by reduced precipitation. In contrast, the increase in potential evapotranspiration due to increased atmospheric waterholding capacity, a secondary impact of warming, works to increase aridity over the humid monsoon region despite an enhanced water supply and relatively less warming. Our results show significant drying effects of warming over the hu-
\end{abstract}

mid monsoon region in recent decades; this also supports the drying trends over warm and water-sufficient regions in future climate.

\section{Introduction}

The background dryness over land varies as climate changes, but the major climate parameter driving dryness changes remains unclear in many regions (Sherwood and $\mathrm{Fu}, 2014$; Hegerl et al., 2015). In previous assessments, precipitation $(P)$, the amount of water supply, is regarded as a key variable for understanding variations in dryness, particularly in humid regions such as Asian monsoon regions (Wang et al., 2012; Kitoh et al., 2013; Liu and Allan, 2013). For example, in eastern Asia, dryness changes are generally summarized as the dry northwestern region (west of $100^{\circ} \mathrm{E}$ and north of $30^{\circ} \mathrm{N}$ ) is getting wetter, the dry northern region (east of $100^{\circ} \mathrm{E}$ and north of $35^{\circ} \mathrm{N}$ ) is getting drier, and the wet southeastern region (east of $100^{\circ} \mathrm{E}$ and south of $35^{\circ} \mathrm{N}$ ) is getting wetter based on changes in annual mean $P$ (Wang and Ding, 2006; Piao et al., 2010). In addition, a decrease in $P$ leads to drying trends over the northern and central-eastern regions 
of India, part of the southern Asian monsoon region (Zhou et al., 2008; Roxy et al., 2015). However, climate change also varies potential evapotranspiration (PET), the amount of atmospheric moisture demand (Liu et al., 2010; Han et al., 2012; Shan et al., 2015). PET variations largely affect dryness trends that are in turn closely related to the occurrence of droughts, water scarcity, and tree mortality (Westerling et al., 2006; Park Williams et al., 2013; Dai, 2013). Drying impacts of PET increase are usually emphasized in water-limited regions (Westerling et al., 2006; Estes et al., 2014); however, humid areas are also expected to experience severe aridification in the 21st century because of a continuous increase in PET (Feng and Fu, 2013; Cook et al., 2014). Thus, the processes involved in the variability in dryness need to be examined in various hydroclimate regimes to better understand continental dryness changes.

This study aims to elucidate the mechanisms of dryness trends in continental eastern Asia through the analysis of observed climate data at 179 and 10 weather stations in mainland China and South Korea, respectively, for the period 1961-2010. The long-term trend in dryness is a critical concern for continental eastern Asia, as it is a region with very large populations, widely varying hydroclimate regimes, fragile ecosystems, and significant agricultural activities (Piao et al., 2010; Geng et al., 2014; Jeong et al., 2014). Also, the analysis region has recently experienced abrupt climate changes (Gong and Ho, 2002; Yue et al., 2013). For example, northeast China experienced severe warming by $0.36^{\circ} \mathrm{C} \mathrm{decade}^{-1}$ for the period of 1960 2006 (Piao et al., 2010). Rainfall intensity has significantly increased over southeastern China (Zhai et al., 2005). Further, changes in the hydrological cycle over eastern Asia are not consistent with the well-known paradigm dry regions drier, wet regions wetter in spite of a significant warming trend (Greve et al., 2014).

Previous assessments on trends in surface dryness show contradictory results over continental eastern Asia. Assessments based on grid reanalysis data generally suggest that continental eastern Asia is getting drier due to an increase in PET accompanied by an increase in the vapor pressure deficit (VPD) (Feng and Fu, 2013; Greve et al., 2014; J. Huang et al., 2016). By contrast, the other studies using site observations reported that more than half of the stations over mainland China show negative trends in both PET / $P$ and PET, indicating a decrease in surface dryness, following a decrease in solar irradiance and wind speed despite continuous warming (Wu et al., 2006; Zhang et al., 2009; H. Huang et al., 2016). Thus, a quantitative analysis is needed to explain the contradiction between previous assessments regarding surface dryness over continental eastern Asia.

In this study, an aridity index, PET / $P$, defined as PET based on the Penman-Monteith method (Allen et al., 1998) divided by $P$, is employed to assess surface dryness and its trends (Estes et al., 2014; Greve et al., 2014). Over the land surface, the amount of actual evaporation (AET) is con-

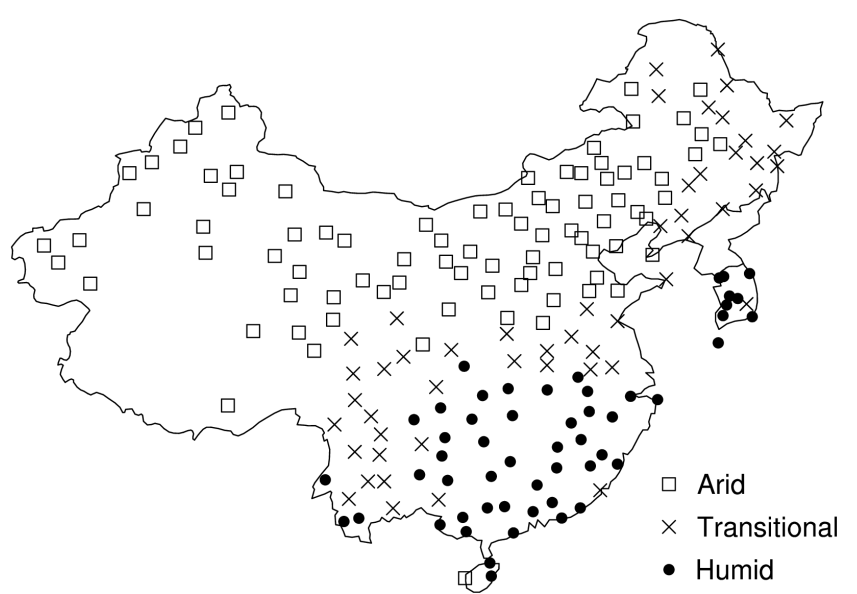

Figure 1. Spatial distribution of 189 meteorological stations in analysis domain. Spatial locations of 179 and 10 meteorological sites of mainland China and South Korea. Empty squares, crosses, and filled circles indicate stations that are classified by arid, transitional, and humid regimes based on 50-year climatological PET / $P$ for the period of 1961-2010.

strained by the amount of $P$, which is also generally less than PET because of limited available water at the surface (Fu and Feng, 2014; Greve et al., 2014). Thus, the PET / $P$ ratio is more suitable for measuring the degree of water deficiency or surplus for a certain climate condition. If the value of PET / $P$ is less than unity, the location is classified as a wet region and vice versa. Likewise, as the aridity index decreases, the land surface becomes wetter and vice versa. By the definition of the aridity index, trends in surface dryness can be resolved by combining the effects of changes in five climate parameters: $P$, net radiation $\left(R_{\mathrm{n}}\right)$, wind speed (WS), surface air temperature $\left(T_{\mathrm{a}}\right)$, and relative humidity $(\mathrm{RH})$. Furthermore, we divide the analysis domain into three hydroclimate regimes based on the 50-year climatology of PET / $P$ : arid (PET $/ P \geq 2)$, transitional $(1 \leq \mathrm{PET} / P<2)$, and humid (PET $/ P<1$ ) (Geng et al., 2014) (Fig. 1). The ratio PET $/ P$ and regional classification allow the identification of climate parameters that are important for trends in surface dryness over the three hydroclimate regimes.

\section{Methods and data}

To compute the aridity index, PET / $P$, climate data for the period 1961-2010 are obtained from 179 and 10 meteorological sites in mainland China and South Korea, respectively. The quality of these data is controlled by the National Meteorological Center of the China Meteorological Administration and Korea Meteorological Administration. Data include daily precipitation, daily mean air temperature, $10 \mathrm{~m}$ wind speed, relative humidity, and sunshine duration. The last four variables are used to compute daily PET following the Penman-Monteith method (Allen et al., 1998; see 

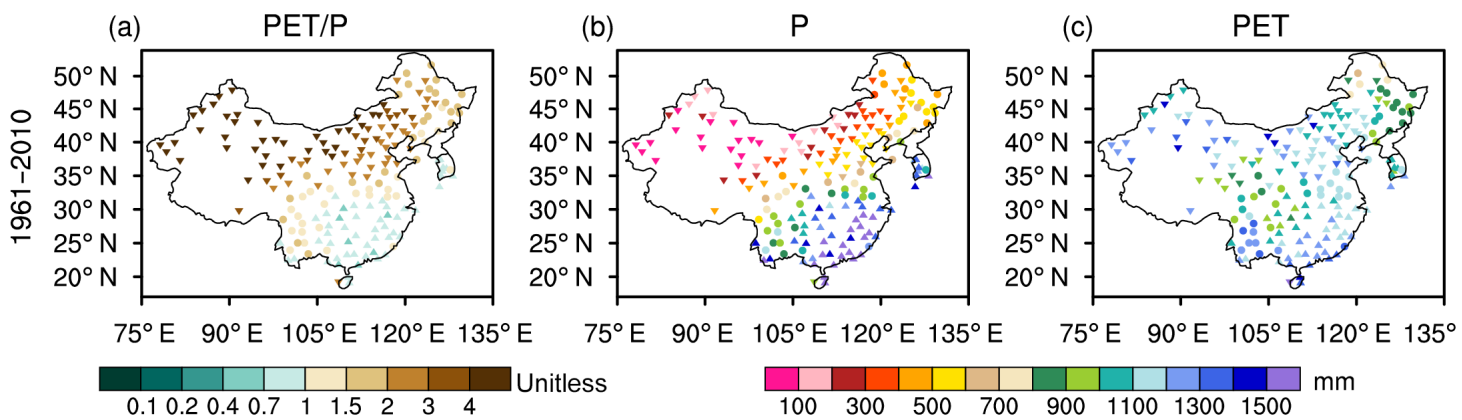

$75^{\circ} \mathrm{E} 90^{\circ} \mathrm{E} 105^{\circ} \mathrm{E} 120^{\circ} \mathrm{E} 135^{\circ} \mathrm{E}$

$75^{\circ} \mathrm{E} 90^{\circ} \mathrm{E} 105^{\circ} \mathrm{E} 120^{\circ} \mathrm{E} 135^{\circ} \mathrm{E}$

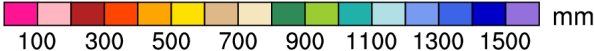

Figure 2. Spatial distributions of the climatologies of PET / $P$ (a), $P(\mathbf{b})$, and PET (c) over continental eastern Asia for the period of 1961-2010. Inverse triangles, circles, and triangles represent stations classified as arid, transitional, and humid regions, respectively.

Sect. S1 in the Supplement for details). We computed the daily PET and PET / $P$ and then estimated their annual mean values at individual weather sites. Due to the decadal variation in eastern Asian monsoon circulation (Ding et al., 2008; Ha et al., 2012), the entire analysis period is divided into two subperiods (1961-1983 and 1984-2010) by applying three change-point methods to the temporal variations in PET / $P$ (Pettitt, 1980; Lund and Reeves, 2002; Beaulieu et al., 2012, see Sect. S2 of Supplement for details). The data at each meteorological site satisfy the following criteria: (1) all climate parameters in the year 2010 exist; (2) sufficient records for at least 10 years for the two subperiods exist (i.e., 1961-1983 and 1984-2010).

To identify the climate variables that contribute most to the observed PET / $P$ trends, relative influences of changes in $P$, $R_{\mathrm{n}}$, WS, $T_{\mathrm{a}}$, and RH on the PET / $P$ trends are computed at individual weather sites based on the derivative of PET $/ P$ with respect to time as follows:

$\frac{\mathrm{d}}{\mathrm{d} t}\left(\frac{\text { PET }}{P}\right)=-\frac{\text { PET }}{P^{2}} \frac{\mathrm{d} P}{\mathrm{~d} t}+\frac{1}{P} \frac{\mathrm{dPET}}{\mathrm{d} t}$.

The first and second terms on the right-hand side indicate temporal changes in the aridity index due to the changes in $P$ and PET. PET can be decomposed into $R_{\mathrm{n}}, \mathrm{WS}, T_{\mathrm{a}}$, and RH using multilinear regression (Chattopadhyay and Hulme, 1997; Yin et al., 2010; Dinpashoh et al., 2011; Han et al., 2012; see Sect. S3 in the Supplement for details). Then, Eq. (1) is written as follows:

$$
\begin{aligned}
& \frac{\mathrm{d}}{\mathrm{d} t}\left(\frac{\mathrm{PET}}{P}\right) \approx-\frac{\overline{\mathrm{PET}}}{\bar{P}^{2}} \frac{\mathrm{d} P}{\mathrm{~d} t} \\
& +\frac{1}{\bar{P}}\left(a_{R_{\mathrm{n}}} \frac{\mathrm{d} R_{\mathrm{n}}}{\mathrm{d} t}+a_{\mathrm{WS}} \frac{\mathrm{dWS}}{\mathrm{d} t}+a_{T_{\mathrm{a}}} \frac{\mathrm{d} T_{\mathrm{a}}}{\mathrm{d} t}+a_{\mathrm{RH}} \frac{\mathrm{dRH}}{\mathrm{d} t}\right),
\end{aligned}
$$

where the terms on the right-hand side are the trend in PET / $P$, considering changes in $P, R_{\mathrm{n}}, \mathrm{WS}, T_{\mathrm{a}}$, and $\mathrm{RH}$, and indicate the relative effects of $P, R_{\mathrm{n}}, \mathrm{WS}, T_{\mathrm{a}}$, and RH, respectively. $\bar{P}$ and $\overline{\mathrm{PET}}$ are the average of the annual mean $P$ and PET for the analysis period, respectively.

\section{Results}

\subsection{Trends in PET / $P, P$, and PET over continental eastern Asia}

Figure 2 shows the climatology of annual mean PET / $P, P$, and PET of all analysis stations over continental eastern Asia for the period of 1961-2010. PET / $P$ varies significantly by region, becoming larger in the northwest and smaller in the southeast (Fig. 2a). This spatial pattern of PET / $P$ is caused by both northwest-southeast patterns of $P$ and small regional variation in PET (Fig. $2 \mathrm{~b}$ and $\mathrm{c}$ ). The annual mean PET $/ P$ is decreased over most of the analysis domain $(86.7 \%$ of total weather stations) during 1961-2010 by both an increase in $P$ and a decrease in PET (Fig. 3). Note that the scale of the $P$ trends (Fig. 3b) is reversed in order to represent drying and wetting trends as red and blue colors, respectively. The negative trends in PET $/ P$ are large and significant at the $95 \%$ confidence level over northwestern China $\left(<100^{\circ} \mathrm{E}\right)$, whereas the eastern part of the analysis domain $\left(>100^{\circ} \mathrm{E}\right)$, classified by monsoon climate zones, shows small and insignificant trends in PET / $P$ (Fig. 3a). The spatial pattern of the trends in $P$ is similar to that of PET / $P$ with opposite sign (Fig. 3a and b). At more than half of the sites, the trends in PET are significant, but the magnitude of PET trends is small (Fig. 3c).

The wetting trends over arid northwestern China are caused by a significant increase in $P$ rather than a decrease in PET (Fig. 3), also consistent with previous assessments (Zhai et al., 2005; Shi et al., 2007; Piao et al., 2010). However, over monsoon climate regions, more detailed analysis is needed due to the decadal variation in large-scale atmospheric circulation and rainfall (Ding et al., 2008; Piao et al., 2010). Figure 4 depicts the temporal variation in the mean PET $/ P$ for the arid, transitional, and humid regimes over monsoon regions $\left(>100^{\circ} \mathrm{E}\right)$ expressed as annual mean anomalies. Note that the temporal variations are the averages of PET / $P$ anomalies at 56, 50, and 51 weather sites located in arid, transitional, and humid climate regimes, respectively. For all three climate regimes, the PET $/ P$ anomalies show 
(a)

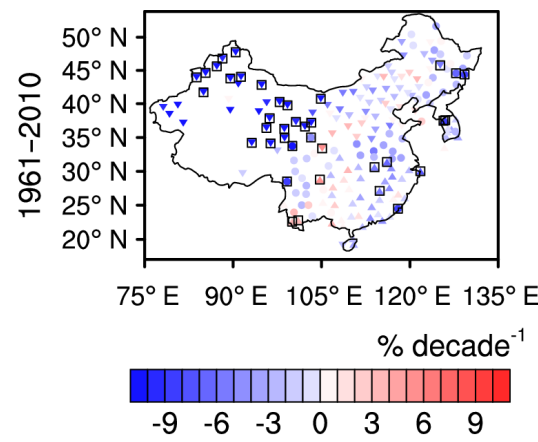

(b)

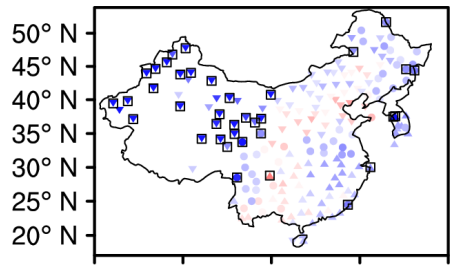

$75^{\circ} \mathrm{E} 90^{\circ} \mathrm{E} 105^{\circ} \mathrm{E} 120^{\circ} \mathrm{E} 135^{\circ} \mathrm{E}$

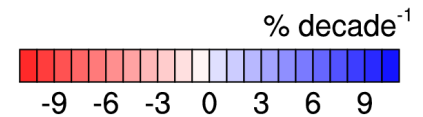

(c)

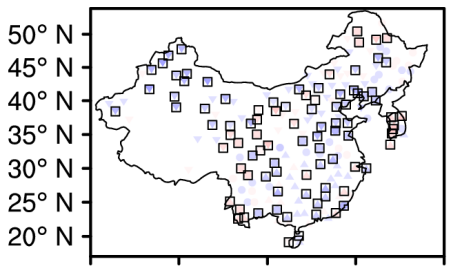

$75^{\circ} \mathrm{E} 90^{\circ} \mathrm{E} 105^{\circ} \mathrm{E} 120^{\circ} \mathrm{E} 135^{\circ} \mathrm{E}$

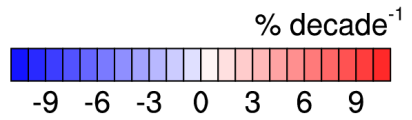

Figure 3. Spatial distributions of the trends in PET / $P, P$, and PET over continental eastern Asia. Panels (a-c): the spatial distribution of trends in the annual mean PET / $P$ (a), $P$ (b), and PET (c) for the period of 1961-2010. Inverse triangles, circles, and triangles represent stations classified as arid, transitional, and humid regions, respectively. The open squares indicate that the trend is significant at the $95 \%$ confidence level.
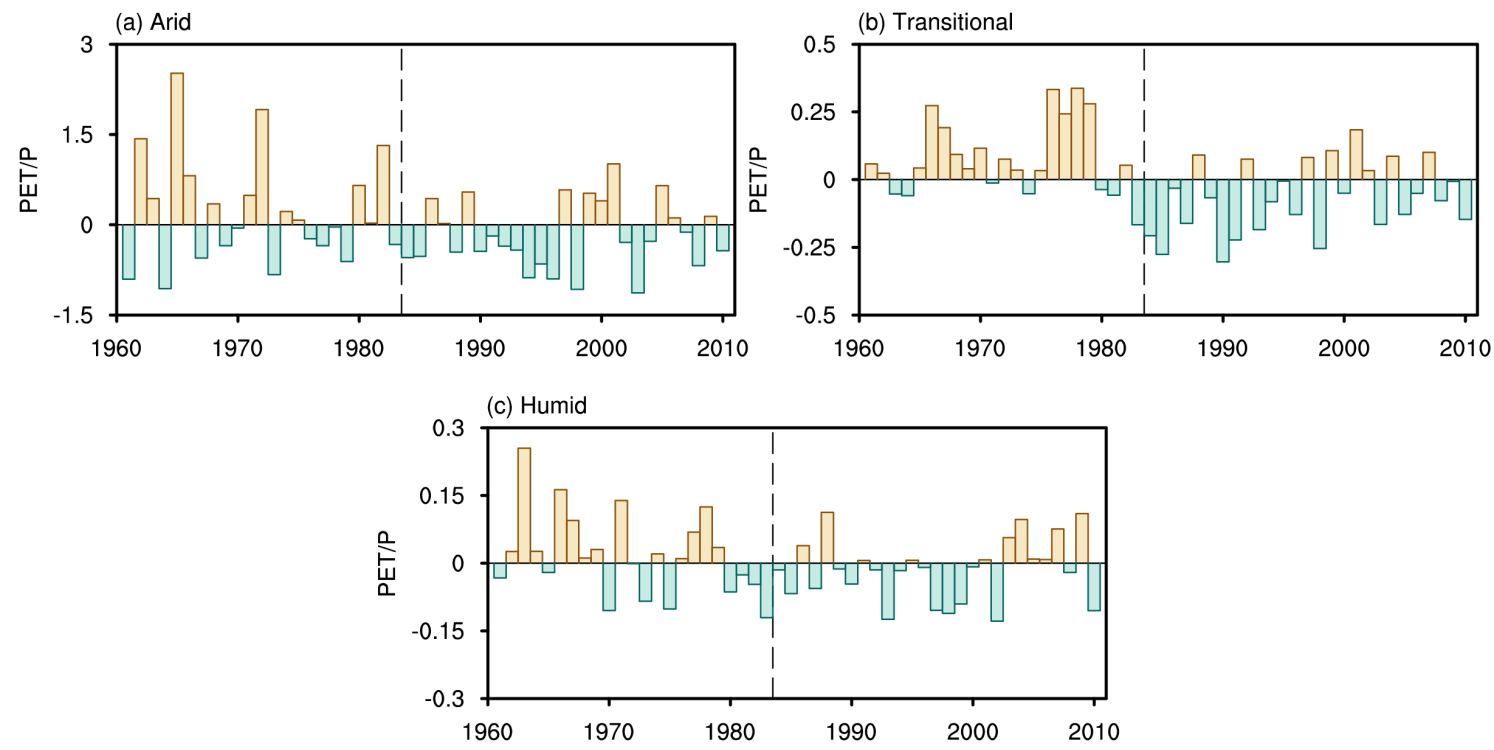

Figure 4. Interannual variations in the annual mean PET / $P$ over the (a) arid, (b) transitional, and (c) humid regions located to the east of $100^{\circ}$ E. Yellow and blue bars indicate the positive and negative anomalies for PET $/ P$, respectively.

abrupt changes in the early 1980s (see Sect. S2 of the Supplement for details). Also, the trends in PET / $P$ anomalies are not significant in the arid and humid regimes. Thus, the analysis of PET / $P$ changes over the monsoon regions needs a separation of the analysis period.

The spatial distributions of PET / $P$ trends show considerable changes between both analysis periods (Fig. 5a and d). For the earlier period, about $60 \%$ of the total number of stations show decreasing trends in PET $/ P$, particularly in the arid (northwestern and northern China) and humid regions (southeastern China) (Fig. 5a). Increasing trends in PET / $P$, with relatively small magnitudes, occur mainly in the transitional region (northeastern and southwestern China). The spatial pattern of the $P$ trend is similar to that of the PET / $P$ trend but with the opposite sign, suggesting that the changes in $P$ are directly linked to changes in PET / $P$ for most of the analysis region (Fig. 5a and b). Decreasing trends in PET appear in more than three-quarters of the analysis domain, but these are significant only in humid regions because of their small magnitudes (Fig. 5a and c).

In the later period, the spatial patterns of the PET $/ P, P$, and PET trends change drastically over the monsoon climate regions (Fig. 5d-f). The trends in PET $/ P$ shift from negative to positive values in both the humid (southeastern China) and arid (northern and northeastern China) regions (Fig. 5a and $\mathrm{d}$ ). These notable alterations to the PET $/ P$ trend are explained by changes in $P$ and PET trends. After the early 1980s, positive trends in $P$ are reversed in the arid regions, and the magnitude of the increasing trends in $P$ decreases in the humid regions (Fig. 5b and e). These changes in $P$ trends 


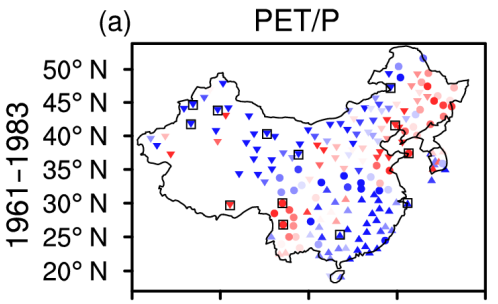

$75^{\circ} \mathrm{E} 90^{\circ} \mathrm{E} 105^{\circ} \mathrm{E} 120^{\circ} \mathrm{E} 135^{\circ} \mathrm{E}$ (d)

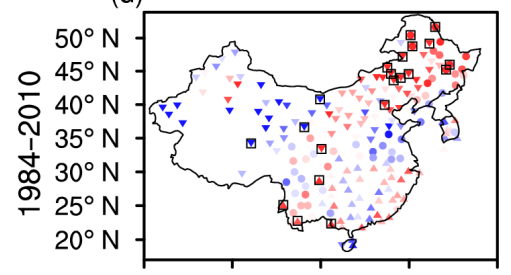

$75^{\circ} \mathrm{E} 90^{\circ} \mathrm{E} 105^{\circ} \mathrm{E} 120^{\circ} \mathrm{E} 135^{\circ} \mathrm{E}$

$\%$ decade $^{-1}$

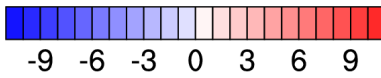

(b)

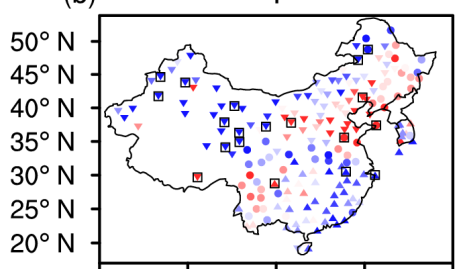

$75^{\circ} \mathrm{E} 90^{\circ} \mathrm{E} 105^{\circ} \mathrm{E} 120^{\circ} \mathrm{E} 135^{\circ} \mathrm{E}$ (e)

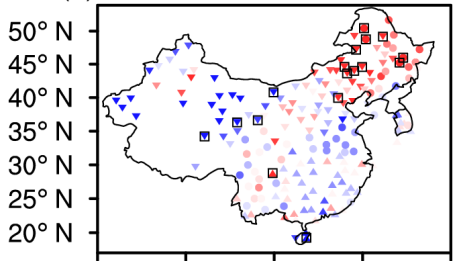

$75^{\circ} \mathrm{E} 90^{\circ} \mathrm{E} 105^{\circ} \mathrm{E} 120^{\circ} \mathrm{E} 135^{\circ} \mathrm{E}$

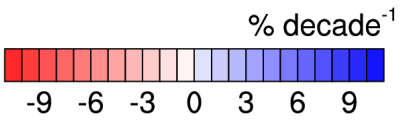

(c)

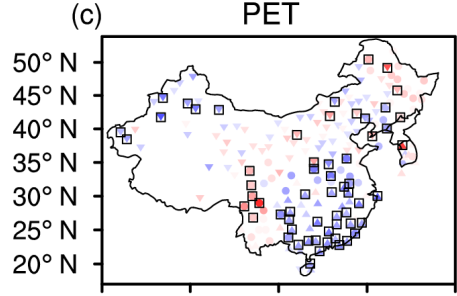

$75^{\circ} \mathrm{E} 90^{\circ} \mathrm{E} 105^{\circ} \mathrm{E} 120^{\circ} \mathrm{E} 135^{\circ} \mathrm{E}$ (f)

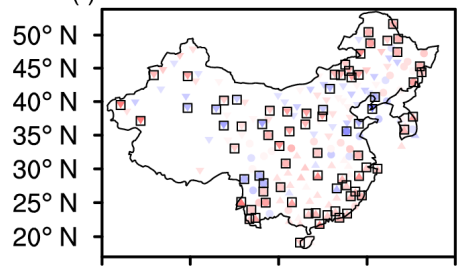

$75^{\circ} \mathrm{E} 90^{\circ} \mathrm{E} 105^{\circ} \mathrm{E} 120^{\circ} \mathrm{E} 135^{\circ} \mathrm{E}$

$\%$ decade $^{-1}$

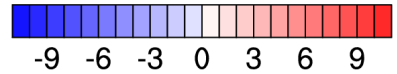

Figure 5. Spatial distributions of the trends in PET $/ P, P$, and PET over continental eastern Asia. (a-c) The spatial distribution of trends in the annual mean PET / $P$ (a), $P$ (b), and PET (c) for the period of 1961-1983. Panels (d-f) as (a-c), but for the period 1984-2010. Inverse triangles, circles, and triangles represent stations classified as arid, transitional, and humid regions, respectively. The open squares indicate that the trend is significant at the $95 \%$ confidence level.

are consistent with those in PET / $P$ trends over the arid regions but not in the humid area (Fig. 5d and e). Significant increases in PET lead to the positive trends in PET / $P$ in the humid area despite the increase in $P$ (Fig. $5 \mathrm{~d}-\mathrm{f}$ ).

The different spatial patterns of PET $/ P$ trends between both analysis periods are consistent with regional patterns of changes in climate variables over eastern Asian monsoon regions. The variations in $P$ are directly associated with the decadal variability in the eastern Asian monsoon circulation. As monsoon circulation weakened, both meridional circulation and southerlies in the lower atmosphere decreased over the eastern Asian monsoon region; hence, moisture transport is concentrated over southern China (Ding et al., 2008). These changes create favorable conditions for rainfall over southern China (humid monsoon region) but opposite situations over northern China (arid monsoon region). Since the late 1970 s, a weakening of monsoon circulation has led to significant decreases and increases in $P$ over arid and humid monsoon regions, respectively (Ding et al., 2008; Piao et al., 2010). The increasing trend in $P$ over the humid area decreases or reverses as a result of the reduction in monsoon rainfall related to the recovery of monsoon circulation after the early 1990s (Liu et al., 2012; Zhu et al., 2012). As a consequence of changes in the monsoon circulation, the decreasing trends in $P$ in the arid region are greater than the increasing trends in the humid area (Fig. 5e). Changes in other climate fields are linked to the positive PET trends (Fig. 5f). For example, the warming trend becomes more severe in the later period (Ge et al., 2013; Yue et al., 2013) (Fig. S3c and g).
The trend in absorbed solar radiation changed from dimming to brightening, particularly in the humid region (Tang et al., 2011) (Fig. S3a and e). Consequently, the combined impacts of changes in climate parameters resulted in the increase in PET / $P$ for 1984-2010.

\subsection{Relative influences of five climate parameters on changes in dryness trends}

Figure 6 shows spatial distribution of the relative influences of five climate variables over continental eastern Asia for 1961-1983 and 1984-2010. Here, positive values of a particular variable indicate increasing rates of PET / $P$ with respect to changes in that variable only and vice versa. Overall, PET / $P$ trends are strongly affected by changes in $P$ in both analysis periods. Influences from the other four variables are generally small but in part comparable to those of $P$. In the early period, changes in $P$ decrease PET $/ P$ in the arid (northwestern China and Inner Mongolia) and humid regions (southeastern China) and also increase PET / $P$ over a part of the transitional (Shandong Peninsula) and arid (Bohai Bay) regions (Fig. 6a). Changes in PET / $P$ due to other climate parameters are negligible except for relatively large influences of $R_{\mathrm{n}}$ over the humid regions (Fig. 6b-e). In the later period, $P$ shows positive influences over northeastern China (arid and transitional regions coexist) but reduces PET / $P$ over the arid (northwestern China) and humid regions (southeastern China) (Fig. 6f). Relative influences of $R_{\mathrm{n}}$ show similar magnitudes to that of $P$ over the transitional 

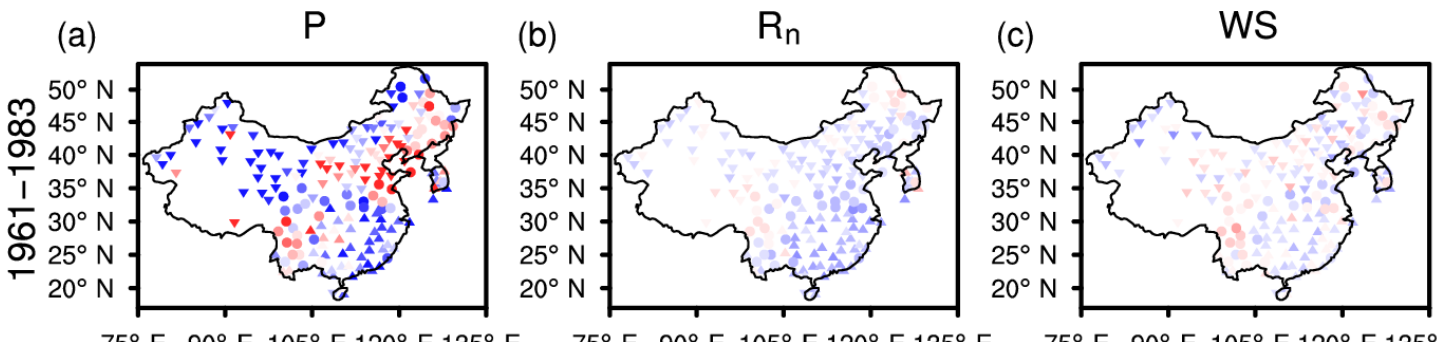

$75^{\circ} \mathrm{E} 90^{\circ} \mathrm{E} 105^{\circ} \mathrm{E} 120^{\circ} \mathrm{E} 135^{\circ} \mathrm{E} \quad 75^{\circ} \mathrm{E} 90^{\circ} \mathrm{E} 105^{\circ} \mathrm{E} 120^{\circ} \mathrm{E} 135^{\circ} \mathrm{E}$

$75^{\circ} \mathrm{E} 90^{\circ} \mathrm{E} 105^{\circ} \mathrm{E} 120^{\circ} \mathrm{E} 135^{\circ} \mathrm{E}$
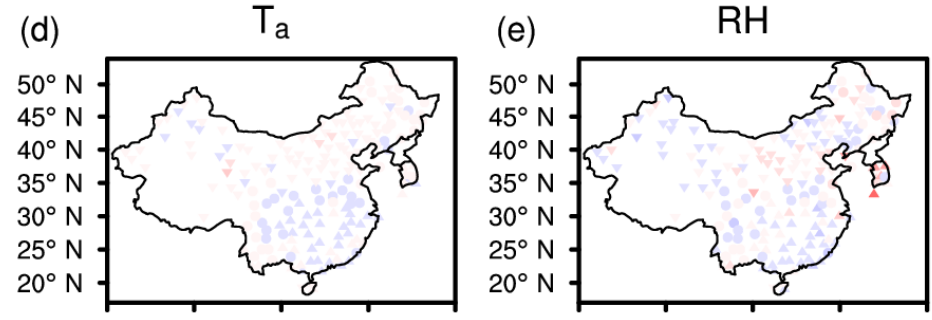

(f)

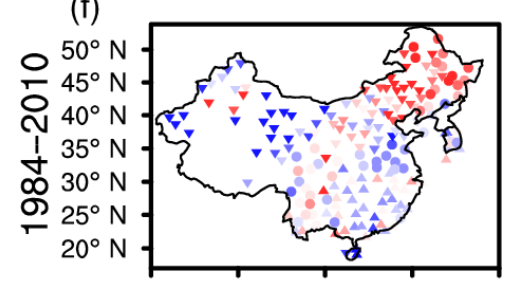

(g)
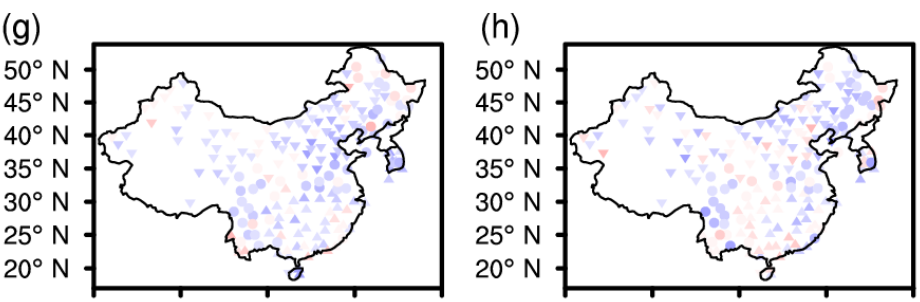

$75^{\circ} \mathrm{E} 90^{\circ} \mathrm{E} 105^{\circ} \mathrm{E} 120^{\circ} \mathrm{E} 135^{\circ} \mathrm{E} \quad 75^{\circ} \mathrm{E} 90^{\circ} \mathrm{E} 105^{\circ} \mathrm{E} 120^{\circ} \mathrm{E} 135^{\circ} \mathrm{E}$

$75^{\circ} \mathrm{E} 90^{\circ} \mathrm{E} 105^{\circ} \mathrm{E} 120^{\circ} \mathrm{E} 135^{\circ} \mathrm{E}$
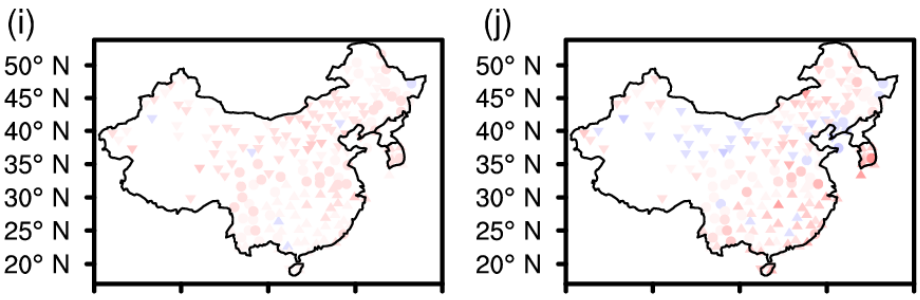

$75^{\circ} \mathrm{E} 90^{\circ} \mathrm{E} 105^{\circ} \mathrm{E} 120^{\circ} \mathrm{E} 135^{\circ} \mathrm{E} \quad 75^{\circ} \mathrm{E} 90^{\circ} \mathrm{E} 105^{\circ} \mathrm{E} 120^{\circ} \mathrm{E} 135^{\circ} \mathrm{E}$

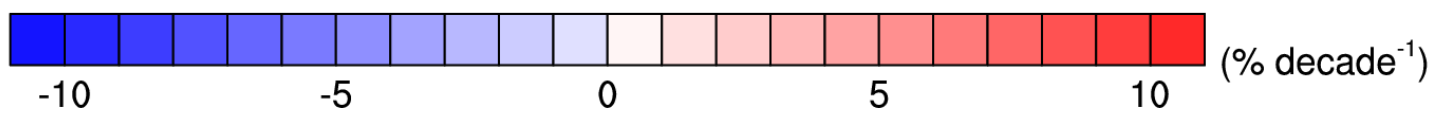

Figure 6. Spatial distributions of the relative influences of five climate parameters on the PET / $P$ trends. (a-e) The spatial distribution of relative influences of the changes in $P(\mathbf{a}), R_{\mathrm{n}}(\mathbf{b})$, WS $(\mathbf{c}), T_{\mathrm{a}}(\mathbf{d})$, and RH (e) on the PET / $P$ trends for the period of 1961-1983. Panels $(\mathbf{f}-\mathbf{j})$ as (a-e) but for the period of 1984-2010. Inverse triangles, circles, and triangles represent stations classified as arid, transitional, and humid regions, respectively.

area (Shandong Peninsula) (Fig. 6f and g). Over the humid regions (southeastern China), positive influences of $\mathrm{RH}$ are on a par with the negative influences of $P$ (Fig. $6 \mathrm{f}$ and $\mathrm{j}$ ).

The spatial patterns of the relative effects of climate parameters are significantly different according to the analysis periods and regions, indicating that the mechanisms involved in changing PET / $P$ trends operate differently. Figure 7 displays the averaged effects of five climate parameters over the three hydroclimate regimes for the two analysis periods. The confidence intervals are computed at the $95 \%$ significance level based on relative influences of five variables at
56,50 , and 51 stations of arid, transitional, and humid climate regimes (see Sect. S3 in the Supplement for details). Note that this analysis focuses on the monsoon region, which shows significant variability in the trends in PET / $P$. Stations located in western China (west of $100^{\circ} \mathrm{E}$ ) are excluded. The mean climate of western China is distinctly different from the monsoon climate (Piao et al., 2010). Furthermore, the dryness trends in these regions are more strongly associated with variations in $P$ for both analysis periods than with other climate variables (Fig. 6 and Zhai et al., 2005; Shi et al., 2007). 
(a) Arid

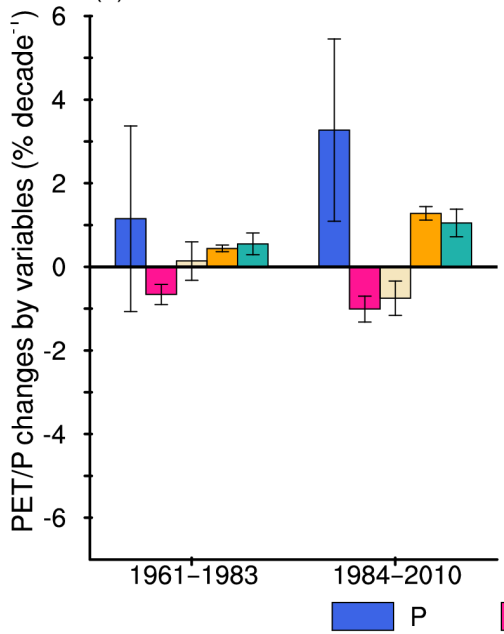

(b) Transitional

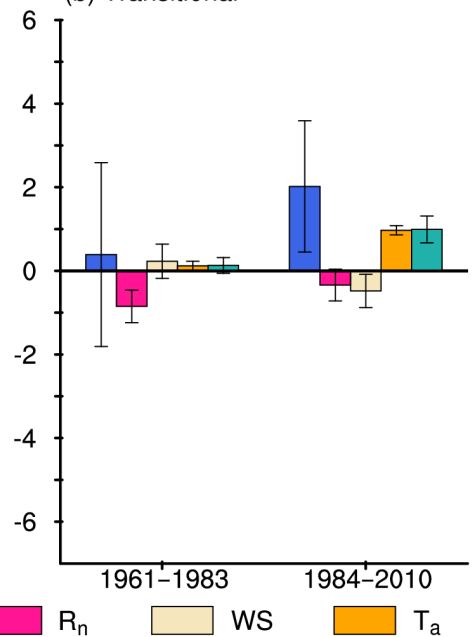

(c) Humid

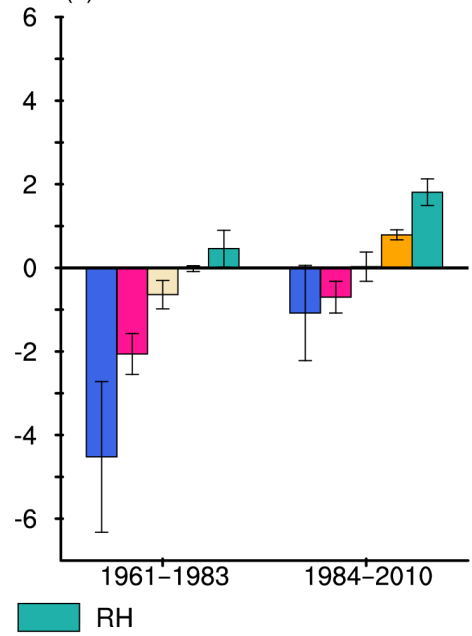

Figure 7. Relative influences ( $\%$ decade $^{-1}$ ) of five climate parameters averaged over the three hydroclimate regimes: arid (a), transitional (b), and humid (c). The influences are computed for two analysis periods: 1961-1983 and 1984-2010. Blue, pink, beige, orange, and cyan bars represent the respective influences of $P, R_{\mathrm{n}}$, WS, $T_{\mathrm{a}}$, and RH. Error bars represent confidence intervals at the $95 \%$ confidence level.

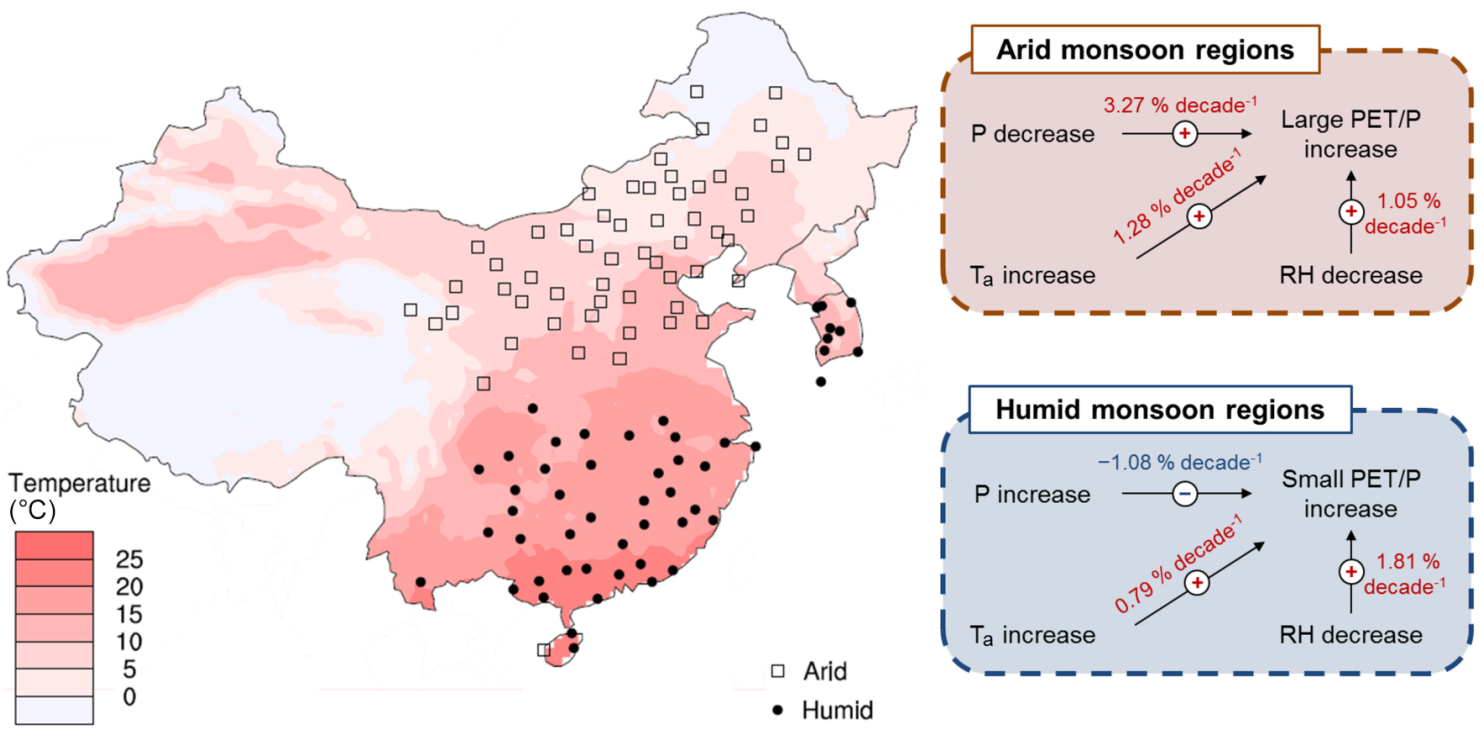

Figure 8. Schematic diagram of the contributions of $P, T_{\mathrm{a}}$, and RH on the PET / $P$ trends in arid and humid monsoon regions for the period of 1983-2010. Diagrams of the influences of $P, T_{\mathrm{a}}$, and RH on the trend in PET / $P$ over arid and humid monsoon regions in 1983-2010 are located to the right of the annual mean temperature over continental eastern Asia for $1961-2010\left({ }^{\circ} \mathrm{C}\right)$. The open squares and filled circles are stations classified as arid and humid monsoon regions (east of $100^{\circ} \mathrm{E}$ ), respectively.

Over the arid region, the positive effects of $P, T_{\mathrm{a}}$, and RH $\left(1.15,0.44\right.$, and $0.55 \%$ decade $^{-1}$, respectively) increase the PET $/ P$ before the early 1980 s (Fig. 7a). The large confidence range of $P$ indicates a substantial impact of $P$ on the PET $/ P$ trends locally (Fig. 6a). In the later period, the change in $P$ provides the largest influence $\left(3.27 \% \mathrm{decade}^{-1}\right)$, with at least twice the magnitude of any other climate parameter. These results imply that the decrease in $P$ is the main cause of the significantly increasing trend in PET $/ P$ over the arid region. In the transitional region, the negative influence of $R_{\mathrm{n}}\left(-0.85 \%\right.$ decade $\left.^{-1}\right)$ appears to be the largest in the earlier period (Fig. 7b), but the wide confidence interval of $P$ suggests that PET / $P$ trends vary spatially according to the changes in $P$ (Fig. 6a). In the later period, PET / $P$ increased because of the positive influences of changes in $P, T_{\mathrm{a}}$, and RH $(2.02,0.97$, and $0.99 \%$ decade $^{-1}$, respectively), despite the negative effects of $R_{\mathrm{n}}$ and WS ( -0.34 and $-0.48 \%$ decade $^{-1}$, respectively). Thus, the increasing trend in PET $/ P$ in the transitional region is largely a consequence of surface warming (i.e., $T_{\mathrm{a}}$ ) 
and decreases in $P$ and RH. Over the humid area, negative effects of both $P$ and $R_{\mathrm{n}}\left(-4.52\right.$ and $-2.06 \%$ decade $^{-1}$, respectively) lead to the decrease in PET / $P$ in the earlier period (Fig. 7c). The contribution from each of the other three variables is much smaller. In contrast, in the later period, the positive influences of $T_{\mathrm{a}}$ and $\mathrm{RH}\left(0.79\right.$ and $1.81 \%$ decade $^{-1}$, respectively) are somewhat larger than the negative influences of $P$ and $R_{\mathrm{n}}\left(-1.08\right.$ and $-0.70 \%$ decade $^{-1}$, respectively). Thus, the increasing trend in PET / $P$ over the humid region is mainly caused by the warming and subsequent increase in atmospheric water demand.

\section{Discussion and conclusions}

The present study suggests that trends in surface dryness reverse from wetting to drying around the early 1980s over both arid and humid monsoon regions. In addition, major climate parameters determining dryness trends vary by both the analysis period and hydroclimate regime. For the period of 1961-1983, trends in surface dryness are mostly attributed to changes in $P$, regardless of region. A significant decrease in $R_{\mathrm{n}}$ reinforces wetting trends over the humid area by decreasing PET. Large influences of $P$ and $R_{\mathrm{n}}$ on dryness trends are consistent with the results of previous studies on trends in aridity and PET using daily observations of weather (Wu et al., 2006; Han et al., 2012).

In the later period, changes in $P, T_{\mathrm{a}}$, and RH lead to drying trends over the monsoon regions. Figure 8 illustrates the impacts of the three variables on the dryness trend in the arid and humid monsoon regions, respectively. Over the arid monsoon region, PET / $P$ is greatly increased by the positive effects of the three variables, whereas the humid monsoon region shows relatively small increases in PET / $P$ because the positive effects of $T_{\mathrm{a}}$ and $\mathrm{RH}$ are offset by the negative effects of $P$. In contrast to the importance of the effect of evaporative potential on surface dryness in other water-limited regions (Westerling et al., 2006; Estes et al., 2012), the decrease in $P$ plays a dominant role in the increasing PET $/ P$ trends in the arid monsoon region. In the humid monsoon area, the decrease in RH shows the largest effect on the PET / $P$ trend, despite the relatively small magnitude of warming. The relationship between air temperature and saturation vapor pressure $\left(e_{\mathrm{s}}\right)$ (e.g., the Clausius-Clapeyron equation) explains the large influence of the decrease in RH. Due to high mean temperatures in the humid monsoon region (shading in the map in Fig. 8), warming leads to a steep increase in $e_{\mathrm{s}}$ and a subsequent decrease in $\mathrm{RH}$, resulting in a large increase in evapotranspiration.

Our results based on point observations already include various anthropogenic impacts such as land-use-land-cover changes (LULCC) and increased aerosol emissions, which can influence climate and further surface dryness (Menon et al., 2002; Jeong et al., 2009, 2011; Park et al., 2012; Guo et al., 2013). For example, in the later period, positive in- fluences of $P$ are generally inconsistent with negative influences of $R_{\mathrm{n}}$ (Fig. 3a) because the decrease in $P$ is a favorable condition for the increase in $R_{\mathrm{n}}$, which can result in positive influences of $R_{\mathrm{n}}$ on the surface dryness trend. We anticipate that aerosols can play an important role in the decrease in $R_{\mathrm{n}}$ in the arid region by absorbing and scattering solar irradiance. Furthermore, additional heating due to urbanization may cause different trends in atmospheric water demands between urban and rural areas (Han et al., 2012; Ren and Zhou, 2014). However, examining the effects of LULCC and aerosols on trends in surface dryness lies beyond the scope of the present study.

The effects of $T_{\mathrm{a}}$ and $\mathrm{RH}$, which act to dry land surfaces, increased significantly in recent decades in all regions (Figs. 6 and 7). Moreover, over the humid monsoon region, increases in RH show a greater influence on trends in surface dryness than increases in $P$. This is an unusual situation considering the large variability in summer monsoon rainfall over continental eastern Asia. The large influence of RH is supported by strong warming over the humid monsoon area after the early 1980s. This kind of drying mechanism is consistent with that suggested in assessments dealing with changes in surface dryness during the 20th and 21st centuries using reconstructed data and future climate projections (Sherwood and Fu, 2014). Thus, our study might reflect an observed precursor of the projected drying trends over the humid areas in 21st century (Cook et al., 2014; Yin et al., 2015). The present results also indicate that drying of the land surface in response to warming is already in progress, not simply a future risk. Therefore, water management planning must consider the increased water demands associated with warming in order to mitigate water scarcity, even in the wet monsoon regions.

Code and data availability. The codes of NCAR Command Language version 6.3.0, Python, and Interactive Data Language for calculation and climate data are available upon request to the corresponding author Su-Jong Jeong (waterbell77@gmail.com).

\section{The Supplement related to this article is available online at https://doi.org/10.5194/acp-17-10467-2017- supplement.}

Author contributions. C-EP and S-JJ conceived and designed the study, analysed data, and wrote the paper. C-HH wrote the paper. HP analysed data and wrote the paper. SP, JK, and SF helped conceive the study and wrote the paper.

Competing interests. The authors declare that they have no conflict of interest. 
Acknowledgements. Su-Jong Jeong and Chang-Eui Park were supported by the startup funding of the South University of Science and Technology of China. Chang-Hoi Ho and Hoonyoung Park were funded by the Korea Ministry of Environment as part of the "Climate Change Correspondence Program".

Edited by: Timothy Garrett

Reviewed by: two anonymous referees

\section{References}

Allen, R. G., Pereira, L. S., Raes, D., and Smith, M.: Crop evapotranspiration - guidelines for computing crop water requirements - FAO Irrigation and drainage Paper 56, FAO, 1998.

Beaulieu, C., Chen, J., and Sarmiento, J. L.: Change-point analysis as a tool to detect abrupt climate variations, Philos. T. R. Soc. A., 370, 1228-1249, https://doi.org/10.1098/rsta.2011.0383, 2012.

Chattopadhyay, N. and Hulme, M.: Evaporation and potential evapotranspiration in India under conditions of recent and future climate change, Agr. Forest Meteorol., 87, 55-73, 1997.

Cook, B. I., Smerdon, J. E., Seager, R., and Coats, S.: Global warming and 21st century drying, Clim. Dynam., 43, 2607-2627, https://doi.org/10.1007/s00382-014-2075-y, 2014.

Dai, A.: Increasing drought under global warming in observations and models, Nat. Clim. Change, 3, 52-28, https://doi.org/10.1038/nclimate1633, 2013.

Ding, Y., Wang, Z., and Sun, Y.: Inter-decadal variation of the summer precipitation in East China and its association with decreasing Asian summer monsoon. Part I: Observed evidences, Int. J. Climatol., 28, 1139-1161, https://doi.org/10.1002/joc.1615, 2008.

Dinpashoh, Y., Jhajharia, D., Fakheri-Fard, A., Singh, V. P., and Kahya, E.: Trends in reference crop evapotranspiration over Iran, J. Hydrol., 399, 422-423, https://doi.org/10.1016/j.jhydrol.2011.01.021, 2011.

Estes, L. D., Chaney, N. W., Herrera-Estrada, J., Sheffield, J., Caylor, K. K., and Wood, E. F.: Changing water availability during the African maize-growing season, 1979-2010, Environ. Res. Lett., 9, 075005, https://doi.org/10.1088/1748-9326/9/7/075005, 2014.

Feng, S. and Fu, Q.: Expansion of global drylands under a warming climate, Atmos. Chem. Phys., 13, 10081-10094, https://doi.org/10.5194/acp-13-10081-2013, 2013.

Fu, Q. and Feng, S.: Responses of terrestrial aridity to global warming, J. Geophys. Res.-Atmos., 119, 7863-7875, https://doi.org/10.1002/2014JD021608, 2014.

Ge, Q., Wang, F., and Luterbacher, J.: Improved estimation of average warming trend of China from 1951-2010 based on satellite observed land-use data, Clim. Change, 121, 365-379, https://doi.org/10.1007/s10584-013-0867-4, 2013.

Geng, Q. L., Wu, P, Zhang, Q., Zhao, X., and Wang, Y.: Dry/wet climate zoning and delimitation of arid areas of Northwest China based on a data-driven fashion, J. Arid Land., 6, 287-299, https://doi.org/10.1007/s40333-013-0206-7, 2014.

Gong, D.-Y. and Ho, C.-H.: Shift in the summer rainfall over the Yangtze River valley in the late 1970s, Geophys. Res. Lett., 29, 78-1-78-4, https://doi.org/10.1029/2001GL014523, 2002.
Greve. P., Orlowsky, B., Mueller, B., Sheffield, J., Reichstein, M., and Seneviratne, S. I.: Global assessment of trends in wetting and drying over land, Nat. Geosci., 7, 716-721, https://doi.org/10.1038/ngeo2247, 2014.

Guo, L., Highwood, E. J., Shaffrey, L. C., and Turner, A. G.: The effect of regional changes in anthropogenic aerosols on rainfall of the East Asian Summer Monsoon, Atmos. Chem. Phys., 13, 1521-1534, https://doi.org/10.5194/acp-13-1521-2013, 2013.

Ha, K.-J., Heo, K.-Y., Lee, S.-S., Yun, K.-S., and Jhun, J.-G.: Variability in the East Asian Monsoon: a review, Meteorol. Appl., 19, 200-215, https://doi.org/10.1002/met.1320, 2012.

Han, S., Xu, D., and Wang, S.: Decreasing potential evaporation trends in China from 1956 to 2005: accelerated in regions with significant agricultural influence?, Agr. Forest Meteorol., 154155, 44-56, https://doi.org/10.1016/j.agrformet.2011.10.009, 2012.

Hegerl, G. C., Black, E., Allan, R. P., Ingram, W. J., Polson, D., Trenberth, K. E., Chadwick, R. S., Arkin, P. A., Sarojini, B. B., Becker, A., Dai, A., Durack, P. J., Easterling, D., Fowler, H. J., Kendon, E. J., Huffman, G. J., Liu, C., Marsh, R., New, M., Osborn, T. J., Skliris, N., Stott, P. A., Vidale, P.-L., Wijffels, S. E., Wilcox, L. J., Willett, K. M., and Zhang, X.: Challenges in quantifying changes in the global water cycle, B. Am. Meteorol. Soc., 96, 1097-1115, https://doi.org/10.1175/BAMS-D-13$00212.1,2015$.

Huang, H., Han, Y., Cao, M., Song, J., and Xiao, H.: Spatial-temporal variation of aridity index of China during 1960-2013, Adv. Meteorol., 2016, 1536135, https://doi.org/10.1155/2016/1536135, 2016.

Huang, J., Yu, H., Guan, X., Wang, G., and Guo, R.: Accelerated dryland expansion under climate change, Nat. Clim. Change, 6, 166-171, https://doi.org/10.1038/nclimate2837, 2016.

Jeong, S.-J., Ho, C.-H., Kim, K.-Y., and Jeong, J.-H.: Reduction of spring warming over East Asia associated with vegetation feedback, Geophys. Res. Lett., 36, L18705, https://doi.org/10.1029/2009GL039114, 2009.

Jeong, S.-J., Ho, C.-H., Park, T.-W., Kim, J., and Levis, S.: Impact of vegetation feedback on the temperature and its diurnal range over the Northern Hemisphere during summer in a $2 \times \mathrm{CO}_{2}$ climate, Clim. Dyn., 37, 821-833, https://doi.org/10.1007/s00382010-0827-x, 2011.

Jeong, S.-J., Ho, C.-H., Piao, S., Kim, J., Ciais, P., Lee, Y.B., Jhun, J.-G., and Park, S.-K.: Effects of double cropping on summer climate of the North China Plain and neighbouring regions, Nat. Clim. Change, 4, 615-619, https://doi.org/10.1038/nclimate2266, 2014.

Kitoh, A., Endo, H., Krishna, K. K., Cavalcanti, I. F. A., Goswami, P., and Zhou, T.: Monsoons in a changing world: a regional perspective in a global context, J. Geophys. Res.-Atmos., 118, 3053-3065, https://doi.org/10.1002/jgrd.50258, 2013.

Liu, C. and Allan, R. P.: Observed and simulated precipitation responses in wet and dry regions $1850-2100$, Environ. Res. Lett., 8, 034002, https://doi.org/10.1088/1748-9326/8/3/034002, 2013.

Liu, H. W., Zhou, T. J., Zhu, Y. X., and Lin, Y. H.: The strengthening East Asia summer monsoon since the early 1990s, Chinese Sci. Bull., 57, 1553-1558, https://doi.org/10.1007/s11434-012-4991$8,2012$. 
Liu, M., Shen, Y., Zeng, Y., and Liu, C.: Trends of pan evaporation in China in recent 50 years in China. J. Geogr. Sci., 20, 557-568, 2010.

Lund, R. and Reeves, J.: Detection of undocumented changepoints: A revision of the two-phase regression model, J. Climate, 15, 2547-2554, 2002.

Menon, S., Hansen, J., Nazarenko, L., and Luo, Y.: Climate effects of black carbon aerosols in China and India, Science, 297, 22502253, https://doi.org/10.1126/science.1075159, 2002.

Park, C.-E., Ho, C.-H., Jeong, S.-J., Kim, J., and Feng, S.: The potential of vegetation feedback to alleviate climate aridity over the United States associated with a $2 \times \mathrm{CO}_{2}$ climate condition, Clim. Dyn., 38, 1489-1500, https://doi.org/10.1007/s00382-011-1150$\mathrm{x}, 2012$.

Park Williams, A., Allen, C. D., Macalady, A. K., Griffin, D., Woodhouse, C. A., Meko, D. M., Swetnam, T. W., Rauscher, S. A., Seager, R., Grissino-Mayer, H. D., Dean, J. S., Cook, E. R., Gangodagamage, C., Cai, M., and McDowell, N. G.: Temperature as a potent driver of regional forest drought stress and tree mortality, Nat. Clim. Change, 3, 292-297, https://doi.org/10.1038/nclimate1693, 2013.

Pettitt, A. N.: A simple cumulative sum type statistic for the changepoint problem with zero-one observation, Biometrika, 67, 1, 7984, 1980.

Piao, S., Ciais, P., Huang, Y., Shen, Z., Peng, S., Li, J., Zhou, L., Liu, H., Ma, Y., Ding, Y., Friedlingstein, P., Liu, C., Tan, K., Yu, Y., Zhang, T., and Fang, J.: The impacts of climate change on water resources and agriculture in China, Nature, 467, 43-51, https://doi.org/10.1038/nature09364, 2010.

Ren, G. and Zhou, Y.: Urbanization effect on trends of extreme temperature indices of national stations over Mainland China, 19612008, J. Climate, 27, 2340-2360, https://doi.org/10.1175/JCLID-13-00393.1, 2014.

Roxy, M. K., Ritika, K., Terray, P., Murtugudde, R., Ashok, K., and Goswami, B. N.: Drying of Indian subcontinent by rapid Indian Ocean warming and a weakening land-sea thermal gradient, Nat. Commun., 6, 7423, https://doi.org/10.1038/ncomms8423, 2015.

Shan, N., Shi, Z., Yang, X., Zhang, X, Guo, H, Zhang, B., and Zhang, Z.: Trends in potential evapotranspiration from 1960 to 2013 for a desertification-prone region of China, Int. J. Climatol., 10, 3434-3445, https://doi.org/10.1002/joc.4566, 2015.

Sherwood, S. and Fu, Q.: A drier future?, Science, 343, 737-739, https://doi.org/10.1126/science.1247620, 2014.

Shi, Y., Shen, Y., Kang, E., Li, D., Ding, Y., Zhang, G., and Hu, R.: Recent and future climate change in Northwest China, Climatic Change, 80, 379-393, https://doi.org/10.1007/s10584-006-91217, 2007.
Tang, W.-J., Yang, K., Qin, J., Cheng, C. C. K., and He, J.: Solar radiation trend across China in recent decades: a revisit with quality-controlled data, Atmos. Chem. Phys., 11, 393-406, https://doi.org/10.5194/acp-11-393-2011, 2011.

Wang, B. and Ding, Q.: Changes in global monsoon precipitation over the past 56 years, Geophys. Res. Lett., 33, L06711, https://doi.org/10.1029/2005GL025347, 2006.

Wang, B., Liu, J., Kim, H.-J., Webster, P. J., and Yim, S.-Y. Recent change of the global monsoon precipitation (1979-2008), Clim. Dynam., 39, 1123-1135, https://doi.org/10.1007/s00382011-1266-z, 2012.

Westerling, A. L., Hidalgo, H. G., Cayan, D. R., and Swetnam, T. W.: Warming and earlier spring increase western U.S. forest wildfire activity, Science, 313, 940-943, https://doi.org/10.1126/science.1128834, 2006.

Wu, S., Yin. Y., Zheng, D., and Yang, Q.: Moisture conditions and climate trends in China during the period 1971-2000, Int. J. Climatol., 26, 193-206, https://doi.org/10.1002/joc.1245, 2006.

Yin, Y., Wu, S., Chen, G., and Dai, E.: Attribution analyses of potential evapotranspiration changes in China since the 1960s, Theor. Appl. Climatol., 101, 19-28, https://doi.org/10.1007/s00704009-0197-7, 2010.

Yin, Y., Ma, D., Wu, S., and Pan, T.: Projections of aridity and its regional variability over China in the mid-21st century, Int. J. Climatol., 14, 4387-4398, https://doi.org/10.1002/joc.4295, 2015.

Yue, T.-X., Zhao, N., Ramsey, R. D., Wang, C.-L., Fan, Z.-Meng, Chen, C.-F., Lu, Y.-M., and Li, B.-L.: Climate change trend in China, with improved accuracy, Climatic Change, 120, 137-151, https://doi.org/10.1007/s10584-013-0785-5, 2013.

Zhai, P. M., Zhang, X. B., Wan, H., and Pan, X. H.: Trends in total precipitation and frequency of daily precipitation extremes over China, J. Climate, 18, 1096-1108, https://doi.org/10.1175/JCLI3318.1, 2005.

Zhang, Q., Xu, C.-Y., and Zhang, Z.-X.: Observed changes of drought/wetness episodes in the Pearl River basin, China, using the standardized precipitation index and aridity index, Theor. Appl. Climatol., 98, 89-99, https://doi.org/10.1007/s00704-0080095-4, 2009.

Zhou, T., Zhang, L., and Li, H.: Changes in global land monsoon area and total rainfall accumulation over the last half century, Geophys. Res. Lett., 35, L16707, https://doi.org/10.1029/2008GL034881, 2008.

Zhu, C., Wang, B., Qian, W., and Zhang, B.: Recent weakening of northern East Asian summer monsoon: a possible response to global warming, Geophys. Res. Lett., 39, L09701, https://doi.org/10.1029/2012GL051155, 2012. 